\title{
Regresso ao Paraíso, de Teixeira de Pascoaes: do "trabalho épico" como reabilitação da epopéia
}

\author{
Juliana Yokoo Garcia*
}

\begin{abstract}
Resumo: Através da análise do poema narrativo Abstract: Through the analysis of the narrative poem Regresso ao Paraíso, de Teixeira de Pascoaes, este Regresso ao Paraíso, by Teixeira de Pascoaes, this estudo pretende apontar as características que o filiam à study aims at pointing out the characteristics that tradição épica, discutindo de que maneira, ainda que affiliate it to the epic tradition, discussing how, despite sofrendo transformações inevitáveis e adaptações a seu passing through inevitable transformations and tempo presente, o poema finda por, através adaptations to its present time, the poem ends up principalmente do que Daniel Madelénat chamou de rehabilitating the epic - a genre considered by some "trabalho épico", reabilitar a epopéia, gênero thinkers from the $19^{\text {th }}$ and $20^{\text {th }}$ centuries as dissonant considerado por alguns estudiosos dos séculos XIX e with modernity -, mainly through what Daniel XX como dissonante à modernidade. Madelénat called "the epic work".
\end{abstract}

Palavras-chaves: Epopéia; poesia narrativa; contexto Keywords: Epic; narrative poetry; cultural context; cultural; século XX. $20^{\text {th }}$ century.

\section{0 “não-lugar” do gênero épico no século XX.}

O século XIX viveu, principalmente em sua segunda metade, grandes mudanças que afetaram diretamente sua produção filosófico-literária. As grandes revoluções (Francesa e Inglesa) e a modernização decorrente destes movimentos, em certa medida, transformaram a visão do homem diante do novo mundo, trazendo à tona uma preocupação maior em voltar o olhar para si e para suas próprias necessidades e, muitas vezes, em criar uma espécie de fuga desta nova realidade.

Esse sentimento individualista, agregado à tentativa de escapar de uma modernidade que não era possível sintetizar, cria uma atmosfera subjetiva que resultará no que, mais tarde, os teóricos da Literatura chamam de Romantismo. Com este movimento não só, mas principalmente literário, a poesia passa a ocupar o lugar de maior destaque no que concerne à expressão do lirismo, do individualismo do ser e suas angústias diante do mundo moderno.

\footnotetext{
Mestranda do Programa de Pós-Graduação em Literatura Portuguesa da Universidade de São Paulo, desenvolvo projeto de pesquisa centrado na Literatura Portuguesa oitocentista sem deixar de atentar a importantes autores portugueses do século XX; bolsista FAPESP a quem agradeço o apoio às pesquisas realizadas. E-mail: juliana_yokoo.garcia@usp.br
} 
Este conceito que alia a poesia ao lirismo será, ao longo da história, mantido como uma espécie de máxima ("poesia = lirismo"), distanciando-se, cada vez mais, o conceito aristotélico de poesia objetiva ou poesia épica.

Em sua A poética clássica (1995), Aristóteles, após definir as diferenças entre tragédia e comédia, detém-se nas características específicas da poesia épica. Para o filósofo, “a Epopéia deve ter as mesmas espécies que a tragédia [...]. Seus componentes, fora a melopéias e o espetáculo, são os mesmos; ela requer, com efeito, peripécias, reconhecimentos e desgraças; ademais, o pensamento e linguagem precisam ser excelentes [...]" (ARISTÓTELES, 1995, p.46).

É exatamente contra toda a objetividade desta poesia que exalta o coletivo objetivo, centrando-se em peripécias de um herói-tipo, que grande parte da poesia do século XIX e XX parece se deter. O caráter individualista e as abstrações dos sentimentos humanos parecem, de fato, estar em dissonância com as características épicas defendidas por Aristóteles.

É de grande valia destacar que, para muitos estudiosos, este objetivismo e o caráter episódico, característicos do gênero épico, são resgatados pelo romance que vê sua ascensão já em fins do século XVIII e sua consolidação no decorrer do XIX. Muito embora o romance, consabidamente, possua seus alicerces naquilo que mais se aproxima do "realismo formal" (diferente do Realismo de escola), há nele, indiscutivelmente, a herança do romanesco, do episódico e da construção do herói. Essas características, tão caras à produção épica parecem, aos olhos dos críticos, perder espaço no gênero poético do conturbado período oitocentista.

Ainda no século XIX, como parte deste movimento literário subjetivo, muitos críticos e poetas defenderam fortemente a morte da poesia épica.

Hegel, Hugo, Poe, Alencar e outros criadores e pensadores da Literatura viam nesta poesia uma forma obsoleta de retratar o mundo; para estes críticos, a épica, com toda sua objetividade e valorização do coletivo, estava em completa dissonância com a Modernidade, uma vez que a estética e psicologia românticas privilegiavam mais a expressão emotiva e confessional do sujeito enquanto indivíduo e da sua interioridade.

A máxima "poesia = lirismo", reforçada pela confirmação crítica da dissonância da épica, resulta, no decorrer dos séculos XIX e XX, em uma espécie de marginalização da epopéia e uma paralisação dos estudos críticos acerca deste gênero. Pelo menos a nível estético-doutrinário, proclama-se a morte e o caráter anacrônico do gênero épico. Chega-se a afirmar, como vimos, que o romance oitocentista toma o lugar da epopéia na vida social moderna. E, pelo menos aparentemente, o espírito revolucionário das vanguardas do princípio do século XX também não parecia ter lugar para o velho gênero épico. 
Contraditoriamente, nesta mesma época em que se defende a morte da epopéia, é possível encontrar textos que, em certa medida, resgatam a forma épica. Essa concomitância gera, portanto, como nos aponta Daniel Madelénat (1986), um paradoxo que se estenderá até os dias de hoje.

Se por um lado os críticos defendem que não é possível construir uma epopéia no mundo moderno, por outro, alguns escritores publicam poemas narrativos longos que, se não reproduzem fielmente as características da épica (e nem poderiam, uma vez que estão inseridos em um contexto histórico completamente diverso), recebem a tradição épica transformando-a e adequando-a a seu tempo presente, resgatando assim elementos essencialmente épicos como os motivos e a própria forma já aqui citada.

Para MADELÉNAT (1986), se a modernidade alcançada a partir de fins do século XIX não permite a existência de uma epopéia, tal qual é concebida pelos estudos clássicos, “conçoit une 'néo-épopée', multiforme, dernière adaptation du genre à l'esprit du temps" (1986, p.232) ${ }^{1}$.

É nesse sentido que podemos encontrar em textos modernos uma forma épica: releitura, transformação e adaptação da épica clássica ao "espírito do tempo". Dessa forma, é possível dizer que se há gêneros literários que entram em decadência, há outros que se transformam, sofrendo metamorfoses e adaptando-se às novas mentalidades e ao novo gosto.

Em outras palavras, um dado é o gênero épico, tal como formalizado desde as poéticas da Antiguidade clássica, com todos os seus códigos; outro dado será certo espírito ou registro épico, que perdura em muitas criações modernas e contemporâneas.

Para além da simples forma épica, é possível também encontrar em alguns textos dos séculos XIX e XX, aquilo que Florence Goyet (apud NEIVA, no prelo) chama "trabalho épico". Ultrapassando o conceito formal, o "trabalho épico" seria uma espécie de valor intrínseco ao texto, que "élabore une vision du monde, ou plus exactement, [...] confronte les visions du monde disponibles à son époque, [...] fait jouer devant le public les options possibles en les développant, de façon à permettre à l'auditeur de juger chacune d'elles."(NEIVA, no prelo) ${ }^{2}$

\footnotetext{
1 “[...] concebe uma 'nova-epopéia’, multiforme, uma última adaptação do gênero ao espírito do tempo"

2 "elabora uma visão de mundo, ou mais exatamente [...] confronta as visões de mundo disponíveis em sua época, [...] na medida em que desenvolve as opções possíveis as faz brincarem diante do público, de maneira a permitir ao leitor/interlocutor julgar cada uma delas"
} 
Assim, para que se possa desenvolver o "trabalho épico" é necessário que o poema esteja em consonância direta com o momento histórico no qual está inserido, ou seja, o poema épico, nesse sentido, é, por excelência, um poema temporalmente determinado.

\section{Regresso ao Paraíso e a reabilitação da epopéia.}

Com o objetivo de mostrar como a Literatura moderna absorveu e transformou a tradição da epopéia, analisaremos, de forma breve, o poema Regresso ao Paraíso (1912) do poeta português Teixeira de Pascoaes (1877-1952) ${ }^{3}$.

Se, de fato, considerarmos relevante que o poema épico e/ou o "trabalho épico" devem estar em consonância e diálogo diretos com seu tempo, torna-se aqui imprescindível estabelecermos um panorama do momento histórico da produção deste poema.

Como bem sintetizou Maria das Graças Moreira de Sá (1992, p.22), Teixeira de Pascoaes viveu no conturbado período de passagem do século XIX para o XX, período este, em Portugal, marcado por um sentimento de decadência, atraso e crise de identidade, agravado, principalmente, pelo Ultimatum inglês de 1890.

Se já a partir da famosa "Geração de 70" havia no espírito literário português o ideal de "integrar Portugal na cultura européia, na senda da Ciência, do Progresso, da Civilização" (SÁ, 1992, p.22), após o Ultimatum inglês, este espírito será agravado por uma reação patriótica de busca por uma nova identidade nacional que vinha sendo perdida desde a fuga da família real para o Brasil em 1807. Dessa forma, a intervenção político-social a partir da Literatura, já iniciada pela geração de 70 - e antes, é importante lembrar, esboçada pela Literatura nacionalista de Garrett - toma novo fôlego, gerando assim um "movimento idealista do fím do século" (SÁ, 1992, p.27).

Já no início do século XX, dando continuidade a este idéia, Pascoaes encabeça o movimento da "Renascença Portuguesa", segundo SÁ, uma espécie de neogarrettianismo que tem por objetivo "revelar a alma lusitana e integrá-la nas suas qualidades essenciais e ordinárias" (1992, p.28).

Para PASCOAES (1973), como veremos a partir da leitura do poema, o renascimento de um novo Portugal dependia, essencialmente, do resgate do sentimento de Saudade, não como hoje o concebemos, mas como um sentimento-idéia sintetizado em um "princípio

\footnotetext{
${ }^{3}$ Para maior simplicidade nas citações da obra de Pascoaes, usamos apenas as iniciais $R P$, seguidas do número de página.
} 
espiritual da Humanidade” (SÁ, 1992, p.28). É, portanto, a partir desta Saudade, que PASCOAES (1973) constrói o "trabalho épico" em seu poema.

Antes de discutirmos de que forma o poeta elabora uma nova visão de mundo, destacaremos algumas características que dão ao poema uma indiscutível forma épica, caracterizando assim uma reabilitação da epopéia.

Essencialmente, o poema narra o mítico percurso de Adão e Eva após a queda do Paraíso. O casal pecador, após ser expulso do Éden, vive em completo esquecimento nas terras de Satã. Sendo os primeiros pecadores do universo, Adão e Eva são 'elevados' à categoria de demônio e diaba, respectivamente. Nesta nova função que lhes é atribuída são incumbidos de voltar à Terra em busca de novos espíritos pecadores. Entretanto, durante esta viagem, ao encontrarem a imagem do filho Caim, começam a lembrar do seu passado paradisíaco. Esta lembrança, aliada ao sentimento de Saudade, faz com que o casal, pouco a pouco, caminhe em regresso ao paraíso perdido.

Em primeiro lugar, faz-se necessário destacar que existe um nexo de intertextualidade clara entre este poema e a clássica epopéia dantesca, A Divina Comédia (1321). Dialogando formalmente com a tradição épica ao organizar seu longo poema narrativo em 22 cantos (embora com versos livres e estrofes irregulares - marcas de sua transformação moderna), PASCOAES (1973) também organiza seu texto em três grandes partes que correspondem às passagens do Inferno ao Paraíso (Inferno - Purgatório - Paraíso, em Dante).

A primeira parte, que abrange os cantos I ao VI, descreve a imagem do Inferno e a vida de Adão e Eva neste inóspito local; já a segunda parte, do canto VII ao XVIII, narra a viagem do casal para a Terra e o início de sua mudança para o "novo mundo"; finalmente, a terceira parte descreve o dia do juízo final e a redenção e retorno de Adão e Eva ao Paraíso 4 .

A partir deste breve resumo, é possível notar que PASCOAES (1973) inspira-se em um motivo bastante recorrente na poesia épica clássica: a descida aos infernos ou catábase. Como sabemos, o tema/motivo da descida aos infernos desenvolve um trabalho alegórico no qual o herói atinge um grau de conhecimento de si mesmo que ignora a concepção de tempo e espaço. É exatamente o que ocorre com os heróis em Regresso ao Paraíso: estão confinados em um espaço não determinado, apenas designado pelo poeta como "aqui”, em um período atemporal dito "agora".

\footnotetext{
${ }^{4}$ Dentro de uma perspectiva intertextual e comparativista, também poderia ser interessante pensar as analogias e as diferenças entre a obra de Teixeira de Pascoaes, Regresso ao Paraíso, e a obra do poeta inglês John Milton, Paraíso Perdido (1667), inserindo assim a obra do autor português numa rica tradição literária inspirada no relato do livro bíblico do Gênesis.
} 
Neste espaço/tempo indeterminados, os heróis (Adão e Eva) de em Regresso ao Paraíso vivem, em um primeiro momento, um estado de total esquecimento. Mais tarde, quando encontram o espectro do filho Caim, entram em um estado de sofrimento profundo, uma vez que se vêem tomados pela lembrança do passado, lembrança esta que nos remete a outro motivo corrente da epopéia ( $\mathrm{O}$ mito da Idade do Ouro - lembrança idealizada da infância/paraíso já perdidos).

É nesta lembrança que encontramos a busca pelo conhecimento ontológico, sintetizada aqui pela imagem da Saudade. Durante o poema, este sentimento-idéia figura uma espécie de salvação, ou ainda, a única salvação possível. É interessante destacar que esta Saudade, segundo Jorge Coutinho equivalente a um "princípio de redenção" (1995, p.133), aparece no poema personificada em uma espécie de Deusa, "a mística Saudade, a Virgem nova, / A Mãe dum novo Deus" (RP, p.80).

A partir da idéia deste novo Deus, cria-se então uma nova concepção da religião cristã, uma vez que o poeta parece sugerir uma renovação em certas crenças; nova concepção, entretanto, não destruidora daquela em voga, mas sim transformadora. Sendo assim, o poema que, claramente, filia-se a uma tradição de poesia cristã (já encontrada em Dante) utiliza imagens do cristianismo, principalmente ao descrever os espaços como o Inferno e o Paraíso perdido ou Éden. Ao primeiro atribui-se a idéia de fogo, calor, violência e sofrimento:

Brandindo no ar um látego de fogo,

Sem piedade, as fustiga e precipita,

Nos grandes, ígneos Lagos infernais,

Abrasadas crateras. (PASCOAES, 1973, p.35)

Ou ainda,

E o seu clamor redobra, ao descobrirem,

O horrível fogo, eternamente aceso,

Donde emergem fantásticas figuras,

Contorcidas, queimadas, desvairadas! (PASCOAES, 1973, p.36).

Ao segundo, a imagem paradisíaca que inspira pureza e inocência:

O encanto do luar e da paisagem,

Sua antiga memória penetrando,

Nela ressuscitaram as primeiras

Horas da vida original,

Quando a luz era Luz, e Flor a flor;

O período da Infância, o Áureo Tempo,

O Ciclo da Inocência... (PASCOAES, 1973, p.79).

Entretanto, há certo paganismo no poema, uma vez que condensa em um único espaço - o céu - a existência do Deus cristão e dos Deuses do Olimpo. Em verdade, muito embora 
enraizada na poesia cristã, Regresso ao Paraíso contém uma mensagem que ultrapassa as questões religiosas, tornando-se uma questão ontológica. O poeta parece apontar as falhas das já obsoletas crenças do cristianismo, sugerindo assim um renascimento desta religião a partir da criação de uma nova fé.

Para que possa alcançar este objetivo crítico, o poeta utiliza uma estrutura narrativa paradoxal, proporcionando um diálogo entre aquilo que o cristianismo prega e aquilo que, de fato, é mostrado em sua narrativa. Nesse sentido, na primeira parte do poema, o poeta elabora uma espécie de catálogo (elemento tão caro à epopéia clássica) dos mortos que se encontram no Inferno (cantos I e IV). É interessante notar que, se por um lado, da perspectiva cristã, é comum que pensemos em grandes pecadores habitantes do Inferno, por outro, PASCOAES (1973) oferece-nos uma descrição totalmente positiva dos seres que lá estão, criando a idéia de que todas as almas condenadas não mereciam tal condenação e problematizando, portanto, a própria noção cristã do pecado. Através da utilização da estrutura do catálogo, o poeta busca dizer a totalidade, enumerando incansavelmente todos os seres considerados pecadores, que, ao fim, parecem, em verdade, sintetizar todos os seres vivos do universo (com exceção dos deuses).

Como forma de reforçar essa idéia e integrar a si e ao próprio leitor neste catálogo, o poeta se coloca no Inferno enquanto observador - assim como o fez Dante em sua Divina Comédia - e define Adão e Eva como "nossos primeiros pais" (PASCOAES, 1973, p.169). Outra forma de problematizar o cristianismo em voga é a contraposição entre um Deus cristão chamado de "velho Deus" ("Aquele velho Deus, irado e resplendente, / Que outrora me expulsou do Paraíso" (Ibidem, p.145), ou ainda, “[...] Deus velhinho, que divaga / Melancólico e triste, nos seus vastos / Jardins paradisíacos" (Ibidem, p.153)) e um "Deus Infante" (Figura "[...] / Formosa e adolescente, / De brandas formas, prestes a atingir / A mácula expressão...” (Ibidem, p.156). Este novo Deus, lembre-se, filho da Virgem Saudade, proporcionará, ao final do poema, a redenção de Adão e Eva e de todos os seres vivos condenados pelo "velho Deus irado".

Nesse momento - caracterizado, de forma cristã, como o dia do juízo final - toda a concepção de pecado cristão é desconstruída e transformada, proporcionando aos seres que regressem, não ao Paraíso perdido, mas sim a um novo Paraíso, pois são novos seres, perdoados pelo novo Deus.

Esta idéia de renovação está, aliás, durante todo o poema, sintetizada e identificada pela utilização do adjetivo "novo" em contraposição direta com o adjetivo "velho", como já apontado quando da descrição dos Deuses. Nesse sentido o novo Adão, transformado pelo 
sentimento da Saudade, mãe do novo Deus, possui "Um novo coração e um novo amor, / E, para além das trevas infernais, / Já via despontar o novo sol / Do novo Paraíso" (Ibidem, p.113). Mais tarde, os dois amantes caminham "Para a vida dum novo Sentimento... /A nova Religião adivinhada" (Ibidem, p.117).

Se, de fato, fica clara a idéia de desconstrução das leis cristãs em voga no período, é possível também interpretar o poema de forma alegórica. Nessa visão, Adão e Eva enquanto heróis desta viagem representam não simplesmente heróis individuais, mas uma coletividade, ou ainda, o Homem, como afirma Adão: “- Eu sou o Homem; mas eles são os homens..." (Ibidem, p.172).

Se pensarmos, portanto, nos heróis como representativos do Homem, é possível afirmar que o poema desenvolve o já citado "trabalho épico". Temos aqui, de fato, a elaboração de uma nova visão de mundo que busca proporcionar ao leitor uma reflexão sobre o mundo presente, como tentativa de transformar o futuro.

Em certa medida, neste aspecto de desenvolvimento do "trabalho épico", podemos afirmar que a essência da epopéia clássica é mantida, uma vez que a ela se atribui uma representação do passado coletivo com a finalidade de proporcionar uma reflexão e com o objetivo/função de relegar para o futuro uma construção simbólica do passado. Nesse sentido, para que se possa desenvolver de forma eficiente o "trabalho épico" é imprescindível que se desenvolva também uma representação de presente, de passado e de futuro.

Em Regresso ao Paraíso, temos, de fato, esta representação bastante clara. Inicialmente, um passado representado por uma lembrança mítica do Paraíso perdido (mito da Idade do Ouro); mais tarde um presente caracterizado pelo sofrimento e pela busca por si mesmo (Descida aos infernos ou catábase); e, finalmente, um futuro sonhado como novo mundo - neste caso um novo Paraíso - que só pode ser alcançado a partir do momento em que o ser descobre sua essência: a Saudade ${ }^{5}$.

Segundo Jorge Coutinho, “o 'Passado’ metafísico é o Paraíso, o estado de graça do ser, antes da queda; segue-se-lhe o presente da condição decaída, ou a condição infernal, em processo de redenção; este orienta-se, por sua vez, para o reencontro do 'Passado' no 'Futuro' absoluto em que o círculo se fecha de novo e a redenção se consuma" (COUTINHO, 1995, p.134). Este "encontro do 'passado' no 'futuro"” só é possível a partir da concepção do sentimento-idéia da Saudade como redenção.

\footnotetext{
${ }^{5}$ Para o poeta, Adão e Eva - e, de forma alegórica, o Homem - têm "Seus corpos (eram) feitos, /Não de carne atual, presente e viva, / Mas da própria matéria da Saudade.” (PASCOAES, 1973, p.85).
} 
Durante sua viagem, seja pelo inferno, seja pela terra, Adão e Eva vão, aos poucos, descobrindo-se saudosos e, a partir disso, iniciam um processo de salvação, pois enquanto saudosos tornam-se também esperançosos. Para o poeta "quem de nada se lembra nada espera" (PASCOAES, 1973, p.43), pois “A esperança é saudade do futuro, / A saudade é esperança no passado...” (Ibidem, p.121).

Sendo assim, o poeta parece sugerir ao seu leitor que olhe para seu passado glorioso e, não só vislumbre esta glória, mas, principalmente, cultive uma lembrança saudosa desta, pois somente através da Saudade será possível alcançar um futuro tão ou mais glorioso que o passado já perdido.

Nesse sentido, o poema, indiscutivelmente, elabora seu 'trabalho épico', integrando-se ao projeto literário de PASCOAES (1973) de forma bastante significativa. A forma épica além de trazer ao poema a possibilidade de desenvolver o "trabalho épico" aqui mostrado, traz elementos que sugerem sua universalidade e sua atemporalidade (como o desenvolvimento do motivo da Catábase). Estas características proporcionam uma reflexão que vai além do projeto inicial do Poeta - refletir o Portugal de seu tempo - buscando não somente uma "Renascença Portuguesa”, mas também um renascimento da própria humanidade.

Segundo PASCOAES em seu Prefácio (1973, p.34), o poema sugere a criação de "uma nova Divindade e um novo conceito de justiça", na qual Adão e Eva, representantes do Homem, "regressam ao Paraíso, restituindo-o ao seu antigo esplendor, mas por esforço próprio, quer dizer, por virtude duma nova ação moral desenvolvida na sua alma". Cultivando, assim, uma das principais características da poesia épica, o poema reflete seu presente através de uma construção simbólica de seu passado, vislumbrando no futuro uma renovação e transformação do passado outrora glorioso.

É, sem dúvida, considerando tais características do poema como um claro desenvolvimento do "trabalho épico" que podemos entender Regresso ao Paraíso como um poema épico moderno, uma nova epopéia (neo-épopée), ou ainda, uma reabilitação, indiscutivelmente bem sucedida, da poesia épica.

\section{Referências}

ARISTÓTELES. A Poética Clássica. São Paulo: Cultrix, 1995.

COUTINHO, Jorge. O Pensamento de Teixeira de Pascoaes. Estudo hermenêutico e crítico. Braga: Publicações da Faculdade de Filosofia da Universidade Católica Portuguesa, 1995. 
GOYET, Florence. "L'épopée comme outil intellectuel”. In: NEIVA, Saulo. Déclin \& confins de l'épopée ao XIX ème siècle. Clermont-Ferrant: PUBP [no prelo].

MADELENAT, Daniel. L'épopée. Paris, PUF, 1986.

MOREIRA SÁ, Maria das Graças. Estética da Saudade em Teixeira de Pascoaes. Lisboa: Instituto de Cultura e Língua Portuguesa/Imprensa Nacional Casa da Moeda, 1992.

PASCOAES, Teixeira de. Regresso ao Paraíso. In: Obras Completas - IV volume. Lisboa: Livraria Bertrand, 1973. 